\title{
Biologia Futura: landscape perspectives on farmland biodiversity conservation
}

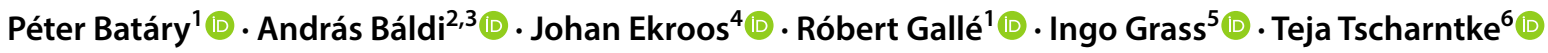

Received: 20 March 2020 / Accepted: 11 May 2020 / Published online: 4 June 2020

(c) The Author(s) 2020

\begin{abstract}
European nature conservation has a strong focus on farmland harbouring threatened species that mainly co-occur with traditional agriculture shaped way before the green revolution. Increased land-use intensity in agriculture has caused an alarming decline in farmland biodiversity during the last century. How can a landscape perspective contribute to fostering our understanding on causes and consequences of farmland biodiversity decline and improving the effectiveness of conservation measures? To answer these questions, we discuss the importance of landscape compositional and configurational heterogeneity, understanding ecological mechanisms determining how landscape structure affects farmland biodiversity and considering the interplay of farmland biodiversity and ecosystem service conservation.
\end{abstract}

Keywords Agri-environment schemes · Ecosystem services $\cdot$ Landscape composition $\cdot$ Landscape configuration $\cdot$ Land sharing $\cdot$ Land sparing

\section{Background}

Global biodiversity conservation cannot rely on protected natural and semi-natural areas alone, as sustainable conservation requires strategies for managing whole landscapes including areas allocated mainly to production or to urban development (Margules and Pressey 2000). This broader approach to conservation is highlighted by the recent Half

Péter Batáry

batary.peter@okologia.mta.hu

1 'Lendület' Landscape and Conservation Ecology, Institute of Ecology and Botany, Centre for Ecological Research, Vácrátót, Hungary

2 'Lendület' Ecosystem Services, Institute of Ecology and Botany, Centre for Ecological Research, Vácrátót, Hungary

3 GINOP Sustainable Ecosystems Group, Centre for Ecological Research, Tihany, Hungary

4 Centre for Environmental and Climate Research, Lund University, Lund, Sweden

5 Department of Ecology of Tropical Agricultural Systems, Institute of Agricultural Sciences in the Tropics, University of Hohenheim, Stuttgart, Germany

6 Agroecology, Department of Crop Sciences, University of Goettingen, Göttingen, Germany
Earth strategy, aiming to set aside half of Earth's surface and devote it for conservation of nature (Watson and Venter 2017). On the one hand, nearly half of the Earth's terrestrial surface is transformed by agriculture, and thus, the contribution of agricultural areas to biodiversity is critical for successful long-term conservation. On the other hand, more than half of human populations live now in cities with urban areas comprising 3\% of the Earth's terrestrial surface (Johnson and Munshi-South 2017).

Agricultural expansion and intensification are among the most important drivers of terrestrial biodiversity loss at local to global scales because of habitat loss, fragmentation and conversion (Tscharntke et al. 2012a). Although even larger areas of Europe were affected by agriculture in the Middle Ages than today, farmland biodiversity was very high because of traditional extensive management. Since the early 20th century, the development of the Haber-Bosch process for the mass-production of nitrogen fertilizers, and, after World War II, the development and large-scale application of synthetic pesticides allowed more intensive and higher-yielding agricultural production. The increasing use of agrochemicals was accompanied by increasing mechanization, which gained much ground during the 1960s (Borlaug's green revolution). In combination, intensification affected agricultural systems at the field scale and across larger spatial scales, including landscapes and entire regions (Tscharntke et al. 2005). Major 
changes between countries took place during the beginning of the cold war, when Europe became divided into East and West. In large parts of the East the collectivization of farms resulted in large co-operatives, where field roads, hedgerows and field margins were eliminated to merge small fields into large-scale agricultural systems within a short time period (Báldi and Batáry 2011). For various reasons, landscape transformation did not affect all eastern countries and regions within countries equally, e.g. because of political or geographical differences (e.g. mountain areas, soil fertility gradients). In addition to differences in soil productivity and historical trajectories of European countries and regions, which led to large heterogeneity between Europe's agricultural landscapes, market forces and the EU's Common Agricultural Policy increased homogeneity in the most productive agricultural regions, affecting the associated biodiversity. The "rangeland" areas in Europe, where both mechanization and agrochemical use failed or were not possible to implement for economic or social reasons, became increasingly abandoned, especially in more economically developed areas of Europe. However, biodiversity conservation often targets the remaining and fragmented natural and semi-natural areas in agricultural landscapes. These areas consist mostly of extensively used grasslands, which often host a high share of threatened species (for example, those listed in the Habitat and Bird Directives of the EU). Nevertheless, land-use change outside natural areas might be responsible for biomass and biodiversity loss in natural areas through isolation and negative flow-on effects (Clough et al. 2014). Thus, a large share of current European nature conservation aims at halting the on-going loss of farmland biodiversity, which has persisted during millennia of extensive management (Gaston 2010).

Because of the multiple pressures on biodiversity, acting on multiple spatial scales, a landscape perspective is needed for effective farmland biodiversity conservation, but how this should be operationalized is not straightforward and is in general highly context dependent (Tscharntke et al. 2012b). Below, we discuss five issues central to a landscape perspective, with a focus on Europe: (1) the importance of disentangling landscape compositional and configurational heterogeneity; (2) the potential suitability of agri-environment schemes (AES) in farmland biodiversity conservation; (3) the mechanisms behind landscape effects; (4) the interplay of biodiversity and ecosystem service conservation; and (5) land-sharing/-sparing connectivity landscapes as a potential idealized solution.

\section{Landscape heterogeneity}

Landscape heterogeneity has been proposed as a key aspect in conserving farmland biodiversity (Benton et al. 2003). Whilst this might be true for intensively managed agricultural landscapes, increasing landscape heterogeneity can also have negative effects on specialist species in more semi-natural and less fragmented, low-intensity agricultural landscapes (Batáry et al. 2011a). Nevertheless, it is necessary to differentiate between two major types of spatial heterogeneity, the landscape compositional heterogeneity and the landscape configurational heterogeneity, to better inform environmentally friendly agricultural policies (Fahrig et al. 2011). Landscape composition refers to the variety and abundance of patch types irrespective of their spatial arrangement (e.g. habitat type richness, proportion of habitat area or diversity of habitat types). Landscape configuration, in contrast, refers to the spatial character and arrangement, position or orientation of landscape elements (e.g. patch shape, distance between patches or mean patch size). Studies investigating the effects of management intensity both at local and landscape scales usually focus on landscape compositional heterogeneity using a gradient of percentage of arable land, non-crop area or semi-natural area (e.g. Batáry et al. 2011b, 2015; but see Batáry et al. 2017). Landscape configuration metrics, such as patch size and isolation, are mostly applied in studies focusing on habitat fragmentation of natural or semi-natural habitats (Lindenmayer and Fischer 2006). However, landscape composition and configuration affect ecological processes independently and interactively (Fahrig et al. 2011). It is therefore important to disentangle landscape composition and configuration effects and to test their potential interactions across different spatial (and temporal) scales. As of today, studies disentangling the effects of compositional and configurational landscape heterogeneity in agroecosystems and especially in urban areas are still scarce, although they have increased (Hadley and Betts 2012).

In intensively used agricultural landscapes, earlier studies focused on the effects of landscape composition on organisms at landscape scales, e.g. proportion of semi-natural habitat (Tscharntke et al. 2005). Meanwhile, several studies investigated the biodiversity patterns of so-called mini habitats under low or no agricultural use, such as semi-natural grassland fragments, hedgerows and flower strips, often with a special focus on their spatial arrangement, i.e. landscape configuration (Tscharntke et al. 2012a). Fahrig et al. (2011) suggested that it is difficult to increase the amount and improve the arrangement of these semi-natural elements due to the need to devote land to agriculture. Therefore, the authors argue, novel approaches should concentrate on increasing the crop heterogeneity itself by (1) decreasing crop field size and (2) increasing crop type diversity (Fig. 1). This approach was recently tested by Sirami et al. (2019), showing that both aspects of crop heterogeneity support multitrophic diversity of farmland biota more than semi-natural cover across several countries. Decreasing field size had a particularly pronounced beneficial effect (ibid.). Martin et al. (2019) considered an interesting combination of these two 
concepts (increasing both semi-natural and crop heterogeneity). They studied the effects of landscape composition (\% semi-natural habitats) and configuration (edge density) on arthropods, showing interactive effects of landscape composition and configuration on arthropod abundances. Interestingly, arthropod abundances were highest in landscapes with high proportions of semi-natural habitats and high edge densities provided by smaller fields, which not only did increase functional biodiversity, but also crop yields. Finally, Batáry et al. (2017) studying the effectiveness of organic farming in small- versus large-scale agricultural regions found that the smaller field sizes are at least as important as organic farming in maintaining farmland biodiversity. Notably, they showed that organic farming produced half of the yield, but two times higher profit than conventional farming due to higher prices of premium organic products. Furthermore, field size did not affect yields, and farmer's profits were much higher in large-scale than in small-scale agriculture probably due to better marketing possibilities because of economies of scale.

In summary, the socioeconomic context influences not only the state of biodiversity across production landscapes, but the entire social-ecological system (Fig. 2; Kremen et al. 2007). These effects are in turn shaped by stakeholders and policy processes at multiple spatial and temporal scales. A social-ecological systems framework has recently enabled researchers to develop a common language that crosses social and ecological disciplines to analyse how interactions among a variety of factors affect outcomes (Hartel et al. 2018). Because of the complex interrelations between biophysical, social, political and economic conditions in agricultural landscapes, it is important to gain a more holistic insight into these factors in order to understand the role of local and landscape predictors on biodiversity and ecological processes (Hanspach et al. 2014).

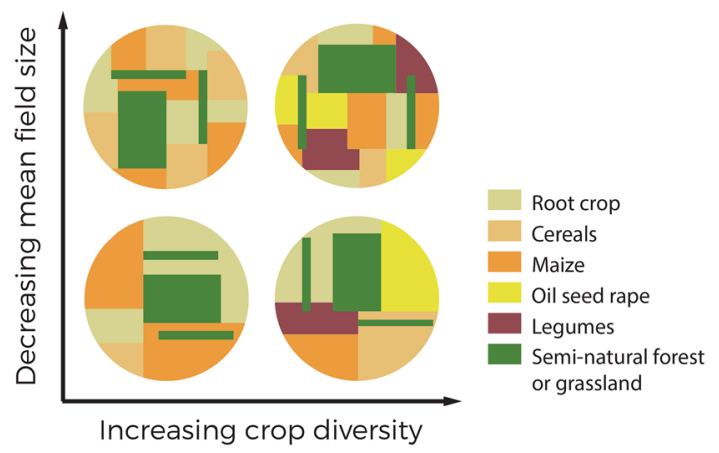

Fig. 1 Increasing compositional (crop diversity) and configurational (field size) landscape heterogeneities focusing on crop heterogeneity and keeping semi-natural habitat amount constant. Modified from Sirami et al. (2019)

\section{Agri-environment schemes}

Implementation of AES is the major tool for farmland conservation in Europe (Batáry et al. 2015). AES include an array of options set up to help farmers manage their land in an environmentally friendly and economically viable way. They are important for the conservation of species-rich farmland, for the preservation of genetic diversity, for the protection of a diversity of agroecosystems types and for producing food with a lower environmental and ecological footprint. Historically, AES were initiated to reduce the overproduction of agriculture by supporting set-aside management in the EU during the late 1980s (Tscharntke et al. 2011). Today, AES rather aim at mitigating negative effects of agricultural intensification and homogenization. Currently, a great variety of AES exists in the 27 members of the EU, as well as the UK, Switzerland and Norway. They can be classified basically in two groups: (1) horizontal (or broad-and-shallow) schemes in all member countries, which combine environmental protection (soil, water) with nature conservation targets, such as organic management; (2) regional (or narrow-and-deep) schemes, which target areas with high nature value for biodiversity conservation (Batáry et al. 2015).

Ideally, research on the effectiveness of AES should explicitly consider how they contribute to increased landscape heterogeneity by introducing habitat or key resources for farmland biodiversity. Although the effectiveness of AES has been questioned from a nature conservation perspective (Kleijn et al. 2001), the accumulated evidence based on metaanalyses shows that AES have a generally positive effect on biodiversity (Batáry et al. 2015). In addition, it has also been increasingly recognized that landscape structure may moderate the effectiveness of AES (Batáry et al. 2011b). One hypothesis is that the schemes are more effective in regions where source populations survive in nearby natural or semi-natural habitats (Duelli and Obrist 2003). In contrast, Tscharntke et al. (2005) hypothesized that AES may be most effective for increasing species richness in simple, but not in complex landscapes, because farms in complex landscapes are likely to already have high species diversity. Based on a meta-analysis, Batáry et al. (2011b) showed that AES are indeed more effective in simple than in complex landscapes. However, this was true only for cropland, and not for grassland studies. Thus, landscape effects differ with ecosystem type considered and in general, the ecological contrast between AES and control sites is decisive whether AES can make a difference (Marja et al. 2019). 


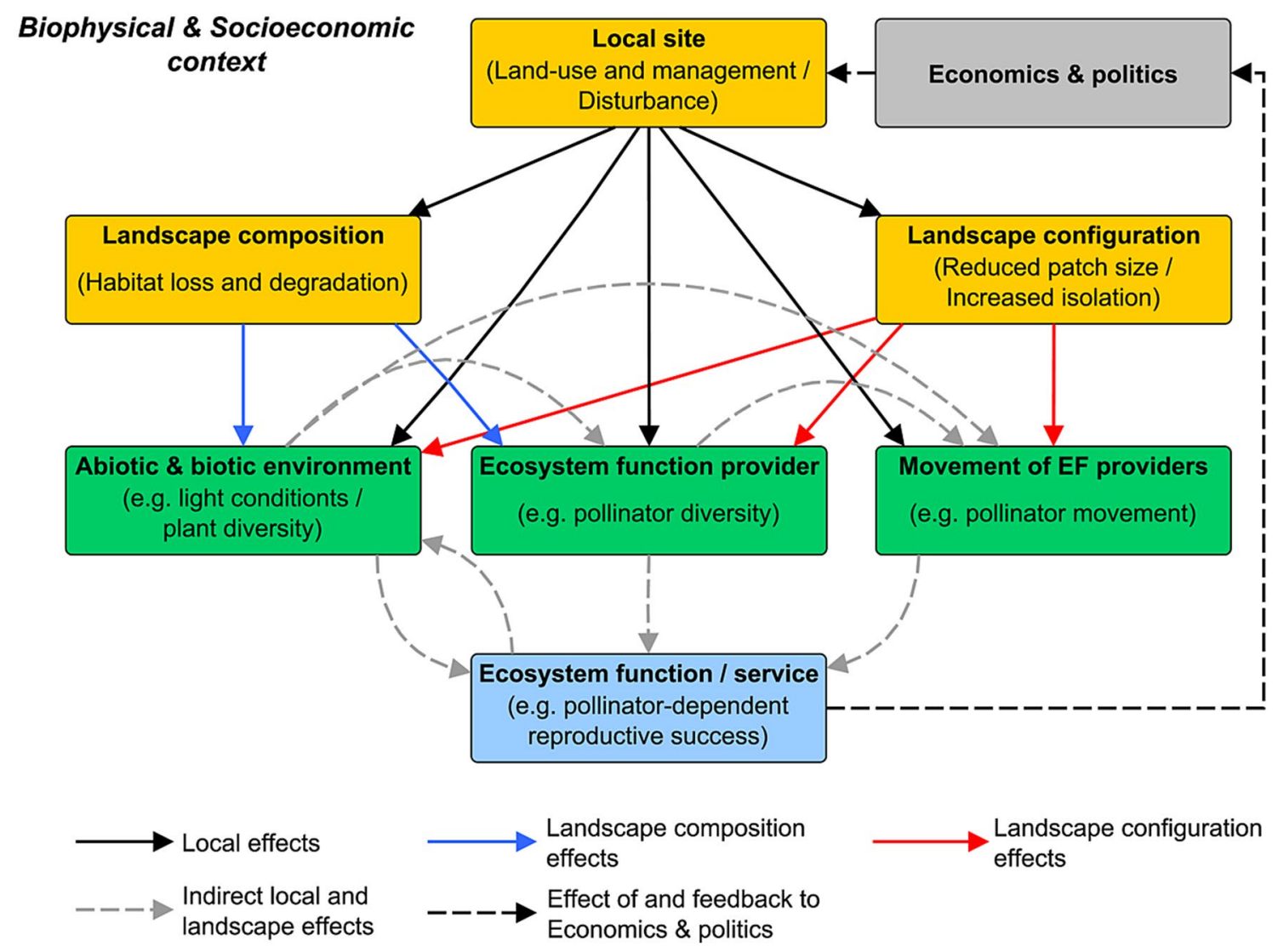

Fig. 2 Conceptual framework for impacts of land-use change on ecosystem functions and services, incorporating market-based forces and policies, and emphasizing the importance of direct and indirect

\section{Mechanisms contributing to landscape effects}

Agricultural systems are commonly characterized by a mosaic landscape structure, where biodiversity may rely on multi-habitat processes such as source-sink dynamics, landscape complementation or spillover effects (Ekroos et al. 2016). Data on species movements between habitats could provide a mechanistic understanding of how landscape structure affects biodiversity (Tscharntke et al. 2012a). Populations may constantly use low quality and unsuitable habitats (sink habitats) through regular colonization from source habitats. The repeated dispersal from source populations may ensure relatively stable abundances in unsuitable habitats, but the existence of sink populations is completely dependent on source populations (Iles et al. 2018). Landscape complementation occurs when populations need at least two non-substitutable, separated resources located across landscapes (Mandelik et al. 2012). For instance, animals may use spatially separated habitats during different life-history stages. Increasing effects of landscape composition and landscape configuration. Modified from Kremen et al. (2007) and Hadley and Betts (2012)

distance between complementary habitats increases the energy required for travelling between habitats; thus, if the complementary habitats are within close proximity, are likely to support relatively high abundances (Haase et al. 2017).

In agroecological studies, especially those focusing on the effects of habitat management, the results are often explained by spillover effects, i.e. the spread of plant propagules and animal individuals from nearby natural, semi-natural or even AES areas into the more intensively used agricultural areas, thus increasing the abundance and species richness of communities within agricultural areas. Invertebrates are known to disperse into arable fields from adjacent natural habitats (Tscharntke et al. 2012a). However, as the high productivity of arable fields during the growing season locally enhances arthropod densities, a massive and large-scale spillover of organisms from crop to non-crop areas can also be expected (Madeira et al. 2016). The potential impact of this spillover on adjacent natural and semi-natural habitats has been largely neglected and is a little understood topic. Spillover of insect predators and 
other functionally important organisms from agricultural to natural habitats and back may have been greatly underestimated (Blitzer et al. 2012).

Different aspects of agricultural intensification do not affect all species equally and depend on species traits, habitat type and spatio-temporal scales (Swift and Hannon 2010). Species surviving in human-dominated landscapes require the ability to use a wide range of resources and disperse between scattered habitat patches. Both local- and landscape-scale intensification select for certain trait states, thereby shaping community composition and ecological functioning including ecosystem services, such as biocontrol or pollination (Martin et al. 2019). Species with traits that disproportionally predispose them to environmental change are those with high habitat or resource specialization and low dispersal ability (Tscharntke et al. 2012a). In order to gain a better understanding of landscape management for multiple functions, it is necessary to analyse different functionally important traits of the studied taxa (Gallé and Batáry 2019), such as reproduction of weed species (insect pollinated vs. wind pollinated, etc.), feeding strategies of carabid and rove beetles (carnivorous, omnivorous, phytophagous, etc.) or hunting strategies of spiders (web-building vs. running). This ecological complexity needs to be considered when evaluating the role of environmental changes, such as habitat degradation, habitat fragmentation or landscape simplification. In order to translate integrated assessments into potential conservation action, stakeholder-relevant conservation targets have to be set up depending on the local socioeconomic context (Fig. 2). A broad implementation of these principles is hampered by the fact that there are no uniform targets for biodiversity conservation and enhancing ecosystem services in different regions and farming systems across the EU.

\section{Trade-offs or synergies between biodiversity conservation versus ecosystem service provisioning}

Biodiversity, in terms of species richness, trait diversity and biotic interactions, affects ecosystem functions and their stability (Cardinale et al. 2012), e.g. by promoting soil supporting services, pollination or biological pest control. In a political context, biodiversity conservation is often justified to ensure human well-being via the supply of ecosystem services. Conserving a wide range of species, including those that are rare and endangered, may serve as an insurance and complementation strategy for safeguarding ecosystem functions under changing environmental conditions. Despite a huge body of experimental approaches (Cardinale et al. 2012), our knowledge about the relationship between biodiversity, ecosystem functions and ecosystem services in human-dominated landscapes is still fragmented and ambiguous. Most likely, this relationship depends upon interacting field and landscape-scale effects (Ekroos et al. 2014).

Despite the general importance of biodiversity for ecosystem functioning, it needs to be acknowledged that not all species contribute equally to ecosystem services at a given time or place. For example, given that only $2 \%$ of pollinator species from regional species pools amount to $80 \%$ of crop pollination services (Kleijn et al. 2015), ecosystem service provisioning is an insufficient argument for pollinator conservation as such. In light of this, Kleijn et al. (2011) proposed in their review two different conservation initiatives. One focuses on conservation of intrinsic biodiversity values, such as rare or endangered species or high biodiversity value habitats in structurally complex landscapes. The other focuses on ecosystem services in structurally simple landscapes independently of species identity. These are roughly equivalent to narrow-and-deep and broad-and-shallow AES. However, a stronger division in these general objectives might not only boost new research, but might also develop more effective AES (Ekroos et al. 2014). Furthermore, Macfadyen et al. (2012) highlighted that actions protecting biodiversity can often indirectly help preserving ecosystem services, but actions enhancing ecosystem services do not necessarily provide good outcomes for biodiversity. Senapathi et al. (2015) view suitability of AES along a curve from ecosystem services to biodiversity conservation with the overall aim of looking for synergies in the middle of the curve (Fig. 3). A recent idea related to enhancement of ecosystem services is the so-called (agro)ecological intensification, which entails the environmentally friendly replacement of anthropogenic inputs and/or enhancement of crop productivity, by including regulating and supporting ecosystem services management in agricultural practices (Bommarco et al. 2013). However, in structurally simple, and hence most likely agriculturally intensive landscapes, the effective broad-and-shallow AES might not increase the ecological contrast needed to improve farmland habitats, because the majority of land in such landscapes relies massively on external input instead of ecosystem services provided by the AES itself. Thus, the distinction between AES targeting biodiversity in general and ecosystem services to agriculture might not only foster the development of more effective AES, but also the transformation of food production more generally (see last sections). This tandem approach would need a stronger involvement and empowerment of key stakeholders, including farmers, farming associations, extension services and other actors, and in general an enhanced governance of AES (Stupak et al. 2019). 


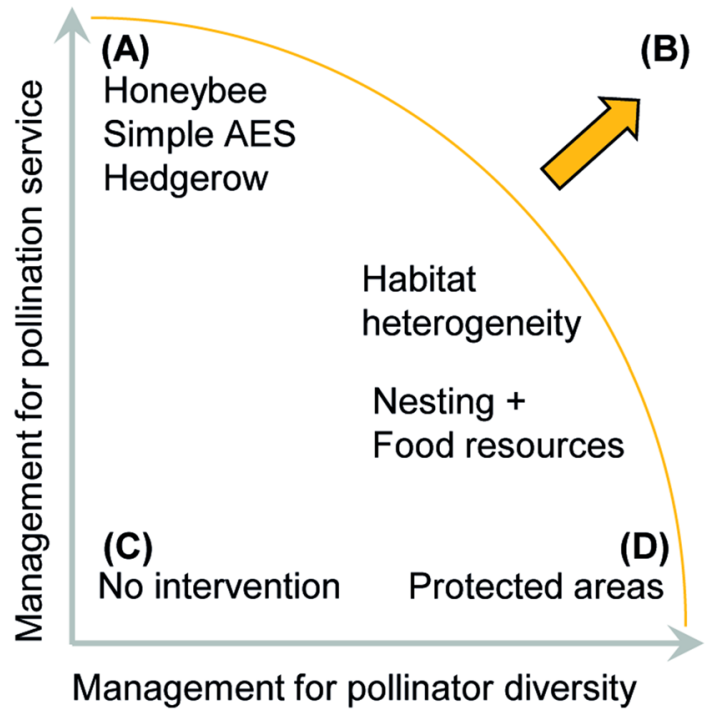

Fig. 3 Schematic figure showing examples of trade-offs between management for pollination services versus management for pollinator conservation. A, B, C and D represent low diversity-high service (loss-win), high diversity-high service (win-win), low diversity-low services (loss-loss) and high diversity-low service (win-loss) scenarios, respectively. Modified from Senapathi et al. (2015)

\section{Land-sharing/-sparing connectivity landscapes}

A parallel emphasis on high agricultural production and biodiversity conservation is a major challenge to humanity. Attempts to reconcile these two aspects ignited a still hot debate, where a spatial segregation of agriculture and nature conservation (land sparing), or a combination of the two, namely integration of agriculture and nature conservation (land sharing), were contrasted against each other (Fischer et al. 2011). A fundamental principle underpinning land sparing is that the majority of biota does not tolerate even the most extensive, nature-friendly management and thus requires segregating strictly protected areas from production landscapes. Land sparing has been claimed to intensify the neighbouring agricultural areas as much as possible to satisfy the food, feed, fibre and fuel (called 4F) demand by humans. Land sparing has been criticized from the points that we do not necessarily have to produce more $4 \mathrm{~F}$, since the supply of these may not be the key issue, but instead a more equitable distribution and less wasting is needed (Tscharntke et al. 2012a). Furthermore, higher yields do not necessarily lessen pressure on spared lands, but instead attract further agricultural exploitation (Angelsen 2010). Moreover, land sharing does not necessarily need more space for achieving a similar yield as land sparing, since there are studies showing how nature-friendly management can enhance both biodiversity and yield (Clough et al. 2011). In the tropics and many other parts of the new world, modern agriculture arrived relatively late, and many of these areas are considered biodiversity hotspots. Thus, in tropical landscapes where rainforests, marshland, etc. are still prevalent, even a low share of less sensitive species could not adapt to modern agriculture, justifying a land sparing strategy. In contrast, in Europe a major focus of nature conservation is targeted to the maintenance and protection of the farmland biodiversity shaped by millennia of traditional extensive management. Fischer et al. (2008) argued that this dichotomy should not viewed as a black and white divide, but rather as a continuum, where the extreme forms can be more or less effective depending on local conditions. They also emphasize three major differences between these two concepts. First, in the case of land sparing, there is a strong contrast between the agricultural and nature protection areas (they are spatially separated but next to each other). In the case of land sharing, this contrast is less acute, as agricultural production and nature conservation share the same land. Second, the agricultural areas are much more homogeneous (more intensively and similarly used) in land sparing than in land sharing. Third, the different land-use elements and their biodiversity values are typically considered at much finer and smaller spatial scales in land sharing than in land sparing. We think that the two latter points can be debated in some situations, e.g. in the case of large, low-intensity semi-natural grasslands, which can be characterized by high biodiversity, but relatively homogenous areas, such as the Pannonian steppe ("Puszta") of Eastern Central Europe (Batáry et al. 2011a).

We believe research on land sparing versus land sharing should increasingly consider multiple conservation strategies, including how to maintain functionally important organisms in agricultural landscapes (Ekroos et al. 2014). Grass et al. (2019) recently suggested a combination of local land sharing and land sparing strategies, which might well work in small-scaled heterogeneous landscapes (Fig. 4). In this sense, land sharing, such as organic farming, but also local-scale land sparing, such as hedgerows or wild flower strips, can significantly contribute to the maintenance of ecosystem service provisioning organisms through spillover or landscape complementation processes (pollinators, biocontrol organisms). Land sparing could support the immigration of them (spillover from production land to semi-natural habitats) and provide habitat for overwintering. Finally, land sparing, even if at small, local scale, could contribute to the conservation of species assemblages of larger spared land by providing stepping stones and/or sustaining them at the landscape scale. 
Fig. 4 Land-sharing/-sparing connectivity landscapes represented along a sharing-sparing continuum and spatial scale gradient. The combination in land-sharing/-sparing connectivity landscapes promotes both biodiversity conservation and the provisioning of ecosystem services. The connectivity matrix ensures (1) spillover from (spared) natural habitats to agroecosystems as well as (2) spillover from (shared) crop boundaries to agroecosystems. In addition, (3) landscape connectivity facilitates immigration and species dispersal, counteracting possible extinctions in spared habitats and providing response diversity in changing environments. Modified from Grass et al. (2019). Photo credits: Péter Batáry, Tibor Hartel and Sinja Zieger

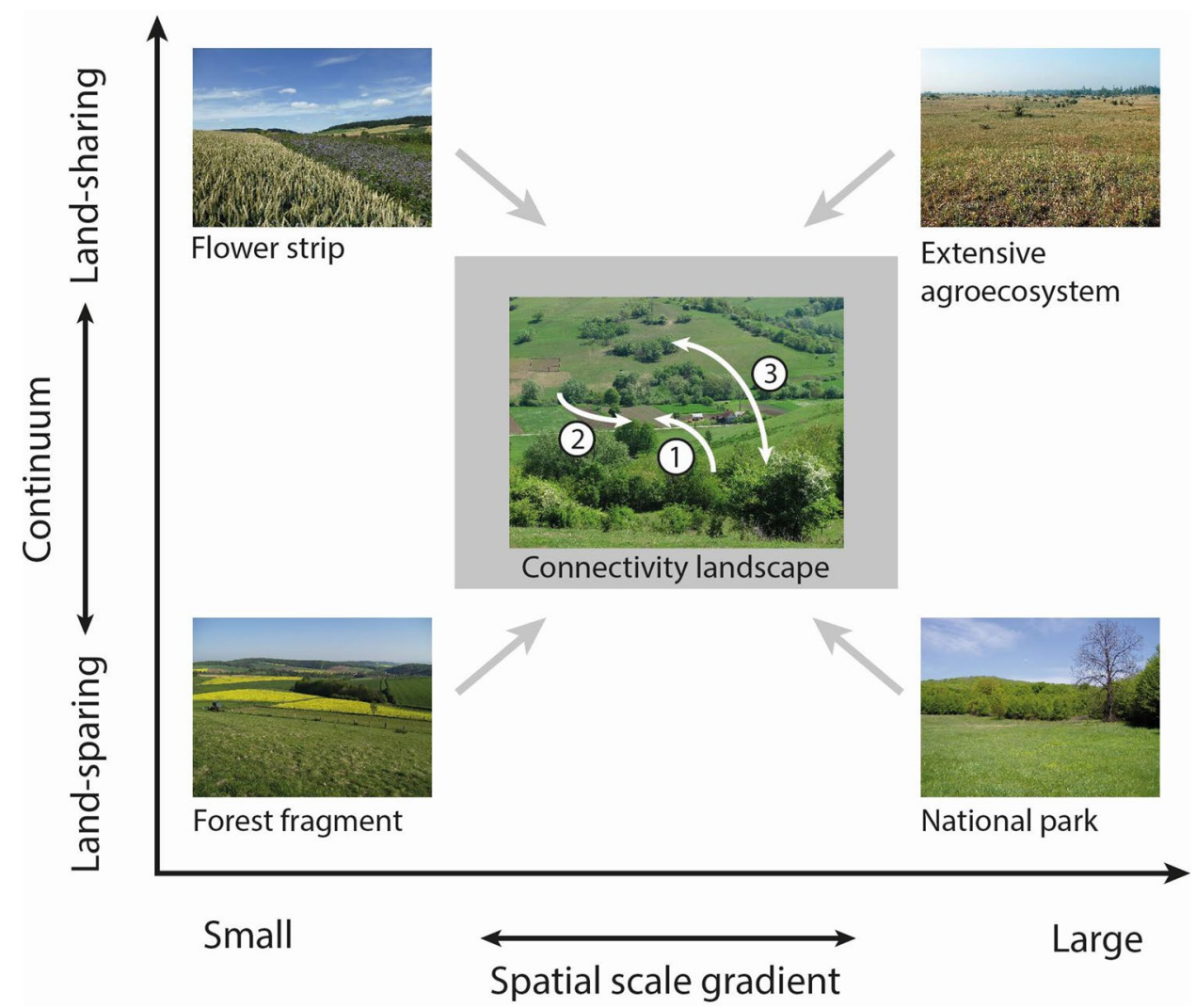

\section{Where could we be in 5-10 years?}

Beyond a hopefully greener path of EU's agriculture policy in the near future (Peer et al. 2019), which will be implemented post-2020, we expect that efforts to promote climate change mitigation may increase incentives to produce biomass for bioenergy in agriculture on marginal agricultural land, in an attempt to avoid competition between bioenergy and food production (Werling et al. 2014). Although a commonly agreed definition of marginal land is lacking, some land belonging to this category may have very high biodiversity values, that a large-scale increase in bioenergy crop production would inadvertently risk eroding (Dauber et al. 2012). Research on what constitutes marginal land, in addition to spatially explicit trade-offs between increasing bioenergy production and biodiversity, will be needed to secure habitat for species of conservation concern and to maintain functional diversity in agricultural landscapes (Dauber and Miyake 2016). Besides the increasing bioenergy production, feed production is one of the important factors of land-use intensification resulting in conflict of food and feed production (Schader et al. 2015). Along the same line, ever increasing urbanization in peri-urban areas also threatens farmland biodiversity (Shaw et al. 2020). Thus, early identification of vulnerable farmland areas under urbanization risk might help spatial planning as well as rural policies (Gottero 2019).

\section{Where we have to be in 2050 ?}

Convincing evidence suggests that the collapse of biodiversity, and degradation of ecosystems can only be avoided if a transformative change in the coming years occurs (Díaz et al. 2019), where a system-wide rearrangement of economy, technology and social value systems happens. Such needs for change already appeared in the Green Deal of the EU (EGD 2020), which urges-among others-that all EU policies should contribute to preserving and restoring nature. There are, however, almost no target numbers for such transformative change. One recent report suggests, however, that roughly two-third of Europe's land need to be restored to push anthropogenic land conversions back under the planetary boundary of land system change (SOER 2019). The $\mathrm{EU}$ also pledged to have zero green-house gas emission by 2050 and declared the wish to reach a low or zero chemicalpesticide use agriculture-all these will lead to drastic landuse changes. Landscape ecology has the potential to provide evidence for decision makers by illustrating how society can benefit from such changes, but also needs to speak up and 
highlight where cuts in current practices or consumption patterns are necessary.

\section{Major questions for landscape ecology and beyond}

Under a best-case scenario, a truly multifunctional European landscape will emerge, providing $4 \mathrm{~F}$, rural well-being and habitat for biodiversity. Landscape heterogeneity has a role in this development. Landscape ecology can contribute with evidence that alleviates trade-offs between different land-use interests, including a wide range of private and public goods. More broadly, we need context-specific tools that can bridge different socio-ecological and historical contexts. In this broader context, we highlight three sets of interrelated questions.

First, can policy consider a landscape perspective, including interventions targeting landscape composition and configuration? Keeping in mind that, as AESs are volunteer based, this might not make sense everywhere. However, collaborative AES can support probably better both key farmland species and ecosystem services than AES targeting individual farms and this way generate landscape-level benefits (McKenzie et al. 2013), including higher revenues for collaborating that work together to create corridors or stepping stones (Batáry et al. 2015). Although, slowly, more and more such AESs are implemented (Groeneveld et al. 2019), and scientific tests of farmers' participation willingness become popular (e.g. Leventon et al. 2017), a coupled test of their ecological, economic and sociological effects in real landscape context need further research.

Second, should there be a more distinct focus on biodiversity conservation versus ecosystem service provisioning? How much biodiversity is needed to sustain ecosystem services? How much natural, semi-natural and agricultural land is needed to sustain biodiversity? Is $20 \%$ habitat in a landscape a threshold value to ensure habitat connectivity and limited extinction (Tscharntke et al. 2002), and how much is this potential threshold value influenced by farmland diversification? There is a high need of more multi-taxon and multi-service studies along different landscape compositional and configurational heterogeneity gradients in the frame of transdisciplinary research projects involving farmers and other actors, which consider also economic outcomes, such as profit for farmers in order to bridge the science and practice gap (Kleijn et al. 2019). Beyond profit trade-offs (Batáry et al. 2017), social aspects, including externalities and perhaps also lost possibilities for recreation could be considered, i.e. farmers might be engaged by social incentives, such as certification programmes (Tscharntke et al. 2015).
Finally, and perhaps most challenging, we need to understand the links between landscape transformation in Europe, including potential positive effects on the local environment and European consumers and producers, in relation to increasing human populations and demands at a global scale. Thus, we argue that landscape ecology has to closely connect with agroecology, agronomy and political sciences to reach a meaningful policy impact. Finally, we believe that landscape ecology can contribute with answers and options to several fundamental questions on how future landscapes in Europe will benefit people and nature, given that funding for landscape-scale experiments on interdisciplinary research programmes can be maintained.

Acknowledgements Open access funding provided by Centre for Ecological Research.

Funding $\mathrm{PB}$ and $\mathrm{AB}$ were supported by the Economic Development and Innovation Operational Programme of Hungary (GINOP-2.3.2-15-2016-00019).

\section{Compliance with ethical standards}

Conflict of interest The authors declare that they have no conflict of interest.

Open Access This article is licensed under a Creative Commons Attribution 4.0 International License, which permits use, sharing, adaptation, distribution and reproduction in any medium or format, as long as you give appropriate credit to the original author(s) and the source, provide a link to the Creative Commons licence, and indicate if changes were made. The images or other third party material in this article are included in the article's Creative Commons licence, unless indicated otherwise in a credit line to the material. If material is not included in the article's Creative Commons licence and your intended use is not permitted by statutory regulation or exceeds the permitted use, you will need to obtain permission directly from the copyright holder. To view a copy of this licence, visit http://creativecommons.org/licenses/by/4.0/.

\section{References}

Angelsen A (2010) Policies for reduced deforestation and their impact on agricultural production. Proc Natl Acad Sci USA 107:19639-19644

Báldi A, Batáry P (2011) Spatial heterogeneity and farmland birds: different perspectives in Western and Eastern Europe. Ibis 153:875-876

Batáry P, Báldi A, Kleijn D, Tscharntke T (2011a) Landscape-moderated biodiversity effects of agri-environmental management-a meta-analysis. Proc R Soc B 278:1894-1902

Batáry P, Fischer J, Báldi A, Crist TO, Tscharntke T (2011b) Does habitat heterogeneity increase farmland biodiversity? Front Ecol Environ 9:152-153

Batáry P, Dicks LV, Kleijn D, Sutherland WJ (2015) The role of agrienvironment schemes in conservation and environmental management. Conserv Biol 29:1006-1016

Batáry P, Gallé R, Riesch F, Fischer C, Dormann CF, Mußhoff O et al (2017) The former iron curtain still drives biodiversity-profit trade-offs in German agriculture. Nat Ecol Evol 1:1279-1284 
Benton TG, Vickery JA, Wilson JD (2003) Farmland biodiversity: is habitat heterogeneity the key? Trends Ecol Evol 18:182-188

Blitzer EJ, Dormann CF, Holzschuh A, Kleijn A-M, Rand TA, Tscharntke $T$ (2012) Spillover of functionally important organisms between managed and natural habitats. Agric Ecosyst Environ 146:34-43

Bommarco R, Kleijn D, Potts SG (2013) Ecological intensification: harnessing ecosystem services for food security. Trends Ecol Evol 28:230-238

Cardinale BJ, Duffy JE, Gonzalez A, Hooper DU, Perrings C, Narwani A et al (2012) Biodiversity loss and its impact on humanity. Nature 486:59-67

Clough Y, Barkmann J, Juhrbandt J, Kessler M, Wanger TC, Anshary A et al (2011) Combining high biodiversity with high yields in tropical agroforests. Proc Natl Acad Sci USA 108:8311-8316

Clough Y, Ekroos J, Báldi A, Batáry P, Bommarco R, Gross N et al (2014) Density of insect-pollinated grassland plants decreases with increasing surrounding land-use intensity. Ecol Lett 17:1168-1177

Dauber J, Miyake S (2016) To integrate or to segregate food crop and energy crop cultivation at the landscape scale? Perspectives on biodiversity conservation in agriculture in Europe. Energy Sustain Soc 6:25

Dauber J, Brown C, Fernando AL, Finnan J, Krasuska E, Ponitka J et al (2012) Bioenergy from "surplus" land: environmental and socio-economic implications. BioRisk 7:5-50

Díaz S, Settele J, Brondízio ES, Ngo HT, Agard J, Arneth A et al (2019) Pervasive human-driven decline of life on Earth points to the need for transformative change. Science 366:1327

Duelli P, Obrist MK (2003) Regional biodiversity in an agricultural landscape: the contribution of seminatural habitat. Basic Appl Ecol 4:129-138

EGD (2020) A European green deal. Striving to be the first climateneutral continent. https://ec.europa.eu/info/strategy/priorities -2019-2024/european-green-deal_en. Accesses 17 Mar 2020

Ekroos J, Olsson O, Rundlöf M, Wätzold F, Smith HG (2014) Optimizing agri-environment schemes for biodiversity, ecosystem services or both? Biol Conserv 172:65-71

Ekroos J, Ödman AM, Andersson GKS, Birkhofer K, Herbertsson L, Klatt BK et al (2016) Sparing land for biodiversity at multiple spatial scales. Front Ecol Evol 3:145

Fahrig L, Baudry J, Brotons L, Burel FG, Crist TO, Fuller RJ et al (2011) Functional landscape heterogeneity and animal biodiversity in agricultural landscapes. Ecol Lett 14:101-112

Fischer J, Brosi B, Daily GC, Ehrlich PR, Goldmann R, Goldstein J et al (2008) Should agricultural policies encourage land sparing or wildlife-friendly farming? Front Ecol Environ 6:380-385

Fischer J, Batáry P, Bawa KS, Brusaard L, Chappel MJ, Clough Y et al (2011) Limits of land sparing. Science 334:593

Gallé R, Batáry P (2019) Trait-based paradise-about the importance of real functionality. Commun Ecol 20:314-316

Gaston KJ (2010) Valuing common species. Science 327:154-155

Gottero E (2019) Identifying vulnerable farmland: an index to capture high urbanisation risk areas. Ecol Indic 98:61-67

Grass I, Loos J, Baensch S, Batáry P, Librán-Embid F, Ficiciyan A et al (2019) Land-sharing/-sparing connectivity landscapes for ecosystem services and biodiversity conservation. People Nat 1:261-272

Groeneveld AN, Peerlings JHM, Bakker MM, Polman NBP, Heijman WJM (2019) Effects on participation and biodiversity of reforming the implementation of agri-environmental schemes in the Netherlands. Ecol Complex 40:100726

Haase CG, Fletcher RJ, Slone DH, Reid JP, Butler SM (2017) Landscape complementation revealed through bipartite networks: an example with the Florida manatee. Landsc Ecol 32:1999-2014

Hadley AS, Betts MG (2012) The effects of landscape fragmentation on pollination dynamics: absence of evidence not evidence of absence. Biol Rev 87:526-544
Hanspach J, Hartel T, Milcu AI, Mikulcak F, Dorresteijn I, Loos J et al (2014) A holistic approach to studying social-ecological systems and its application to southern Transylvania. Ecol Soc 19:32

Hartel T, Fagerholm N, Torralba M, Balázsi Á, Plieninger T (2018) Social-ecological system archetypes for European rangelands. Rangel Ecol Manag 71:536-544

Iles DT, Williams NM, Crone EE (2018) Source-sink dynamics of bumblebees in rapidly changing landscapes. J Appl Ecol 55:2802-2811

Johnson MTJ, Munshi-South J (2017) Evolution of life in urban environments. Science 358:607

Kleijn D, Berendse F, Smit R, Gilissen N (2001) Agri-environment schemes do not effectively protect biodiversity in Dutch agricultural landscapes. Nature 413:723-725

Kleijn D, Rundlöf M, Scheper J, Smith HG, Tscharntke T (2011) Does conservation on farmland contribute to halting the biodiversity decline? Trends Ecol Evol 26:474-481

Kleijn D, Winfree R, Bartomeus I, Carvalheiro LG, Henry M, Isaacs R et al (2015) Delivery of crop pollination services is an insufficient argument for wild pollinator conservation. Nat Commun 6:7414

Kleijn D, Bommarco R, Fijen TPM, Garibaldi LA, Potts SG, van der Putten WH (2019) Ecological intensification: bridging the gap between science and practice. Trends Ecol Evol 34:154-166

Kremen C, Neal MW, Aizen MA, Gemmill-Herren B, LeBuhn G, Minckley $\mathrm{R}$ et al (2007) Pollination and other ecosystem services produced by mobile organisms: a conceptual framework for the effects of landuse change. Ecol Lett 10:299-314

Leventon J, Schaal T, Velten S, Dänhardt J, Fischer J, Abson DJ et al (2017) Collaboration or fragmentation? Biodiversity management through the common agricultural policy. Land Use Policy 64:1-12

Lindenmayer DB, Fischer J (2006) Habitat fragmentation and landscape change: an ecological and conservation synthesis. Island Press, Washington

Macfadyen S, Cunningham SA, Costamagna AC, Schellhorn NA (2012) Managing ecosystem services and biodiversity conservation in agricultural landscapes: Are the solutions the same? J Appl Ecol 49:690-694

Madeira F, Tscharntke T, Elek Z, Kormann UG, Pons X, Rösch V et al (2016) Spillover of arthropods from cropland to protected calcareous grassland - the neighbouring habitat matters. Agric Ecosyst Environ 235:127-133

Mandelik Y, Winfree R, Neeson T, Kremen C (2012) Complementary habitat use by wild bees in agro-natural landscapes. Ecol Appl 22:1535-1546

Margules CR, Pressey RL (2000) Systematic conservation planning. Nature 405:243-253

Marja R, Kleijn D, Tscharntke T, Klein A-M, Frank T, Batáry P (2019) Effectiveness of agri-environmental management on pollinators is moderated more by ecological contrast than by landscape structure or land-use intensity. Ecol Lett 22:1493-1500

Martin EA, Dainese M, Clough Y, Báldi A, Bommarco R, Gagic V et al (2019) The interplay of landscape composition and configuration: new pathways to manage functional biodiversity and agroecosystem services across Europe. Ecol Lett 22:1083-1094

McKenzie AJ, Emery SB, Franks JR, Whittingham MJ (2013) Landscape-scale conservation: collaborative agri-environment schemes could benefit both biodiversity and ecosystem services, but will farmers be willing to participate? J Appl Ecol 50:1274-1280

Peer G, Zinngrebe Y, Moreira F, Sirami C, Schindler S, Müller R et al (2019) A greener path for the EU Common Agricultural Policy. Science 365:449-451

Schader C, Muller A, El-Hage Scialabba N, Hecht J, Isensee A, Erb KH et al (2015) Impacts of feeding less food-competing feedstuffs to livestock on global food system sustainability. J R Soc Interface 12:20150891

Senapathi D, Biesmeijer JC, Breeze TD, Kleijn D, Potts SG, Carvalheiro LG (2015) Pollinator conservation - the difference between 
managing for pollination services and preserving pollinator diversity. Curr Opin Insect Sci 12:93-101

Shaw BJ, van Vliet J, Verburg PH (2020) The peri-urbanization of Europe: a systematic review of a multifaceted process. Landsc Urban Plan 196:103733

Sirami C, Gross N, Bosem Baillod A, Bertrand C, Carrié R, Hass A et al (2019) Increasing crop heterogeneity enhances multitrophic diversity across agricultural regions. Proc Natl Acad Sci USA 116:16442-16447

SOER (2019) The European environment-state and outlook 2020: knowledge for transition to a sustainable. Europe European Environment Agency, Copenhagen

Stupak N, Sanders J, Heinrich B (2019) The role of farmers' understanding of nature in shaping their uptake of nature protection measures. Ecol Econom 157:301-311

Swift TL, Hannon SJ (2010) Critical thresholds associated with habitat loss: a review of the concept, evidence, and applications. Biol Rev $85: 35-53$

Tscharntke T, Steffan-Dewenter I, Kruess A, Thies C (2002) Contribution of small habitat fragments to conservation of insect communities of grassland-cropland landscapes. Ecol Appl 12:354-363

Tscharntke T, Klein A-M, Kruess A, Steffan-Dewenter I, Thies C (2005) Landscape perspectives on agricultural intensification and biodiversity—ecosystem service management. Ecol Lett 8:857-874
Tscharntke T, Batáry P, Dormann CF (2011) Set-aside management: How do succession, sowing patterns and landscape context affect biodiversity? Agric Ecosyst Environ 143:37-44

Tscharntke T, Clough Y, Wanger TC, Jackson L, Motzke I, Perfecto I et al (2012a) Global food security, biodiversity conservation and the future of agricultural intensification. Biol Conserv 151:53-59

Tscharntke T, Tylianakis JM, Rand TA, Didham RK, Fahrig L, Batáry P et al (2012b) Landscape moderation of biodiversity patterns-eight hypotheses. Biol Rev 87:661-685

Tscharntke T, Milder JC, Schroth G, Clough Y, DeClerck F, Waldron A et al (2015) Conserving biodiversity through certification of tropical agroforestry crops at local and landscape scales. Conserv Lett 8:14-23

Watson JEM, Venter O (2017) A global plan for nature conservation. Nature 550:48-49

Werling BP, Dickson TL, Isaacs R, Gaines H, Gratton C, Gross KL et al (2014) Perennial grasslands enhance biodiversity and multiple ecosystem services in bioenergy landscapes. Proc Natl Acad Sci USA 111:1652-1657 